\title{
USO DA TEORIA DOS PÓLOS DE CRESCIMENTO E PÓLOS DE DESENVOLVIMENTO PARA A ELABORAÇÃO DE REDE DE TRANSPORTE MULTIMODAL DE CARGAS PARA A REGIÃO AMAZÔNICA
}

\section{Using the growth and development poles theory to devise a multimodal freight transportation network for amazon region}

\author{
Cristiano Farias Almeida ${ }^{1}$, Yaeko Yamashita ${ }^{2}$
}

Recebido em 29 de abril de 2014; recebido para revisão em 16 de maio de 2014; aceito em 28 de junho de 2014; disponivel on-line em 12 de setembro de 2014.

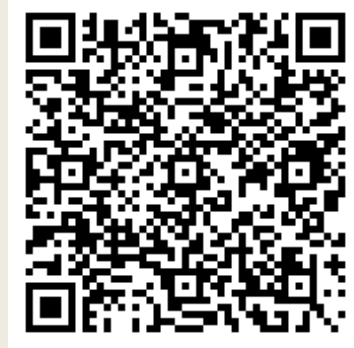

\section{PALAVRAS CHAVE:}

Rede de Transportes;

Teoria dos Pólos de

Crescimento;

Teoria dos Pólos de

Desenvolvimento;

Teoria dos Grafos.

\section{KEYWORDS:}

Transportation Network;

Growth Pole Theory;

Development Poles

Theory;

Graphs Theory.

* Contato com os autores:

RESUMO: A relação entre transporte e desenvolvimento econômico é estudada há anos. No Brasil, especialmente na Região Amazônica, tal enfoque teve iniciou na década de 70 com elaboração de alguns planos e projetos direcionados ao crescimento econômico regional. No entanto, devido alguns fatores, tais como a incompatibilidade entre os modelos propostos de planejamento de transporte e planejamento territorial, os resultados esperados não foram alcançados. Visto que os tomadores de decisões focaram na ocupação territorial e não em modelos de planejamento que explorassem os recursos naturais disponíveis. Sob tal ponto de vista, esse artigo tem como objetivo propor uma rede de transporte multimodal de cargas que proporcione o deslocamento eficiente de produtos. Considerou-se no cenário de pesquisa o uso de recursos naturais disponíveis na área de estudo. A rede proposta permite estimular o crescimento e desenvolvimento econômico regional e foi baseada na Teoria dos Pólos de Crescimento e Pólos de Desenvolvimento e na Teoria dos Grafos, os quais são comumente usadas em estudos de redes de transporte.

ABSTRACT: The relationship between transport and economic development has been studied for years. In Brazil such matter began being studied in the 70's, when several plans and projects for economic development were created. However, due to factors like the incompatibility between the proposed models of transportation planning and territorial planning, the expected results were never achieved. Since the decision makers focused on territorial occupation and do not concerning with transportation planning models that explore the natural resources available. In that view, this paper sets out to devise a multimodal cargo transportation network that enables goods to be efficiently conveyed within a region. The network should be developed using the natural resources available in the area. The proposed network aims at stimulating regional economic growth and development based on the Growth and Development Poles Theory and Graph Theory, which are both commonly used in network transportation studies.

${ }^{1}$ e-mail : cristianofarias@ufg.br (C. F. Almeida )

Doutor em Planejamento de Transporte, Professor do Programa de Pós-Graduação Projeto e Cidade (PPG Projeto e Cidade), Universidade Federal de Goiás (UFG).

2e-mail : yaeko@unb.br (Y. Yamashita)

Doutora em Planejamento de Transporte, Professora da Faculdade de Tecnologia (FT), Universidade de Brasília (UnB). 


\section{INTRODUÇÃO}

Países continentais como o Brasil apresentam grandes regiões em desenvolvimento com imensos recursos naturais disponíveis, tais como a Região Amazônica. Esses países, em função do processo de planejamento não contemplar igualmente todas as regiões, não conseguem atingir níveis de desenvolvimento e crescimento desejavelmente satisfatórios. O planejamento adotado, neste caso, reflete-se em termos de ineficiência inerente principalmente no planejamento regional e nas suas duas vertentes principais: o planejamento dos transportes e o planejamento territorial (Vasconcelos, 2000).

A falta de um modelo de planejamento territorial que se preocupe com a identificação dos centros onde atividades se desenvolvem, ocasiona as principais ineficiências encontradas no processo de planejamento regional (Richardson, 1969; Griffith, 2007; BRASIL, 2008). Essas ineficiências podem gerar a dispersão de grandes núcleos urbanos e de atividades econômicas no espaço geográfico, e consequentemente ocasionar o desordenamento territorial afetando a conexão entre tais pólos e a estrutura do território regional (RODRIGUE et al., 2006; DINIZ, 2013).

As dispersões, nesse caso, são
ocasionadas,
principalmente, incompatibilidade do uso e ocupação do solo com a infraestrutura de transportes, o que reflete nos processos ineficientes de desenvolvimento econômico regional (LOPES, 2001; BANISTER e BERECHMAN, 2001). Tal problema poderia ser solucionado por meio da identificação de atividades econômicas predominantes e relevantes, as quais possibilitariam a identificação de Pólos de Crescimento (ANDRADE, 1987). Esses pólos propagariam o crescimento econômico por intermédio das infraestruturas de transportes, essas por sua vez facilitariam o deslocamento regional (PERROUX, 1964). Assim, seria possível constituir complexa rede de transporte multimodal, contribuindo para o crescimento econômico regional.
A concepção de uma rede de transporte multimodal que promova os deslocamentos de produtos de forma eficiente e impulsione o crescimento econômico de regiões como a Amazônica, sustenta-se, basicamente, em duas fundamentações teóricas: a Teoria dos Pólos de Crescimento e Pólos de Desenvolvimento de Perroux e a Teoria dos Grafos usada em técnicas de elaboração de redes.

Assim, o objetivo deste estudo é propor uma rede de transporte multimodal de cargas que permita o deslocamento dos produtos de uma região de forma eficiente, usando os recursos naturais e de infraestrutura disponíveis. De forma a atingir tal objetivo, nas seções seguintes são apresentados: o embasamento teórico que fundamentou o estudo, assim como a metodologia desenvolvida e sua respectiva validação, e as conclusões.

\section{REVISÃO DA LITERATURA}

A revisão da literatura é constituída por duas bases teóricas, referentes: ao desenvolvimento econômico regional e a teoria dos pólos de crescimento e pólos de desenvolvimento; e a teoria dos grafos.

\subsection{TEORIAS E MODELOS DE DESENVOLVIMENTO ECONÔMICO REGIONAL: UM ENFOQUE GEOECONÔMICO - O ESPAÇO COMO UNIDADE DINÂMICA}

Há tempos que a análise econômica dentro do campo do desenvolvimento regional considera tendências de desagregação das variáveis com que se trabalha. Porém, é necessário que essa desagregação seja conduzida no sentido de privilegiar todas as variáveis, a fim de que as análises atinjam níveis elevados de precisão. $O$ espaço foi uma das variáveis a receber atenção de desagregação de forma tardia, onde, em economia regional, as análises são tais que a explicação dos fatos é apresentada independentemente das localizações espaciais (LOPES, 2001; SANTOS, 2003).

Ao levar em consideração o fator 
espaço na análise do desenvolvimento econômico regional, por meio da existência de interações espaciais das atividades, foram desenvolvidos alguns modelos e teorias que, neste estudo, são considerados como geoeconômicos. Entre os quais se destaca à Teoria dos Pólos de Crescimento e Pólos de Desenvolvimento proposta por Perroux.

\subsubsection{Perroux e as regiões econômicas}

Sobre o aspecto econômico, François Perroux (1964) admite que o espaço possa ser encarado sob três óticas: (i) o espaço econômico como conteúdo de um plano; (ii) o espaço econômico como um campo de forças; (iii) o espaço econômico como um conjunto homogêneo. Como consequências surgem, então, três tipos de regiões econômicas: a região plana, a região polarizada e a região homogênea (HADDAD et al., 1972; CLEMENTE e HIGACHI, 2000).

O conceito de espaço como conteúdo de um plano dá origem a região de planejamento. Assim, um órgão público ou qualquer outro agente econômico possui sua região de planejamento que influencia suas decisões e é afetada por estas. Os planos de desenvolvimento regional são exemplos típicos de delimitação de região de planejamento pelo setor público (CLEMENTE e HIGACHI, 2000). A região polarizada resulta da interdependência existente entre várias áreas, as vezes, pertencentes a regiões homogêneas diversas, devido a influência comercial das aglomerações urbanas (COMBES et al., 2005). A região homogênea corresponde ao espaço contínuo em que cada uma das partes que o constituem apresenta características que a aproximam uma das outras (BOUDEVILLE, 1961; CLEMENTE e HIGACHI, 2000).

$O$ poder de atração que uma cidade exerce em torno da área que a cerca, resultado das relações que realiza com as áreas ou outras cidades, provoca a formação de áreas de influência e de regiões polarizadas. A economia, por meio do comércio, é a atividade regionalizante e, em função dela, se estende o raio de ação das cidades. Por esse motivo, se ampliam ao seu redor as vias de transportes pelas quais aumenta a sua força de atração (SANTOS, 1953).
Observa-se a importância dispensada pelos geógrafos ao núcleo urbano como sendo polarizador, e a rede de transportes como fator de expansão de influência dessa função polarizadora. Em função desse mecanismo surgem e por meio dele se formam os centros regionais e de polarização (LIMA e SIMÕES, 2009).

\subsubsection{Teoria dos pólos de crescimento e pólos de desenvolvimento}

Perroux elaborou a Teoria dos Pólos de Crescimento e de Desenvolvimento baseado em observações, na qual o crescimento econômico não se faz de forma difusa por todo o espaço, mas se manifesta em certos pontos chamados de pólos de crescimento com intensidades variáveis, daí se propagando por diversos canais com efeitos terminais distintos (ANDRADE, 1987).

O pólo de crescimento ocorre devido ao surgimento de uma indústria motriz, sendo esta a indústria que realiza a separação dos fatores da produção, provoca a concentração de capitais sob um mesmo poder e decompõe as tarefas. A indústria motriz tem um crescimento mais elevado do seu produto que o crescimento médio do produto nacional. Esse crescimento não é permanente, mas se faz sentir por certo período de tempo (PERROUX, 1964).

A indústria motriz, em sua ação de ponto de atração para a mão-de-obra e produtora de uma série de produtos, dinamiza a vida regional, atraindo outras indústrias e criando a aglomeração populacional que estimulará o desenvolvimento das atividades agrícolas nas áreas fornecedoras de alimentos e de matérias-primas, além de desenvolver a formação de atividades terciárias (Ferreira, 2012). Surge, o que Perroux chama de complexo industrial, caracterizado pela presença de uma indústria-chave. Dentre as indústrias do complexo, é considerada indústria-chave aquela que proporciona crescimento superior das vendas de outros produtos em relação ao próprio crescimento de suas vendas. As indústrias-chave são quase sempre aquelas que produzem matérias-primas, energia, transporte (ANDRADE, 1987).

Embora Perroux tenha desenvolvido sua 
teoria em função da indústria, decorrente do fato da economia moderna liderada pela atividade industrial e de realizar seus estudos em países industrializados, ele estende a função motriz às atividades primárias, tais como exploração mineral e produção agrícola.

Em resumo, pode-se dizer que, para Perroux, o pólo é o centro econômico dinâmico de uma região, de um país ou de um continente, e que o seu crescimento se faz sentir sobre a região que o cerca, pois este cria fluxos da região para o centro e refluxos do centro para a região. $O$ desenvolvimento regional estará sempre ligado ao desenvolvimento do seu pólo.

\subsection{REDE DE TRANSPORTE}

A história de desenvolvimento das redes surgiu pela necessidade de distribuição de alguns serviços: saneamento, energia elétrica, transporte. Tais redes tinham formatos reticulares e foram classificadas como redes técnicas urbanas, pois eram responsáveis apenas pela distribuição desses serviços em ambientes urbanos onde existia maior concentração populacional, sendo analisadas por meio de fluxos materiais (DUPUY, 1998).

Com o incremento populacional e consequente aumento da demanda por esses serviços, houve a necessidade de se estender as análises para um campo mais amplo, surgindo o conceito moderno de rede. Sob tal ponto de vista, assume-se uma rede de transporte como uma estrutura física constituída por elementos de um sistema de transporte e por elementos abstratos como desejos, ações e relações existentes entre a infraestrutura de transporte e o meio ambiente. O grau do relacionamento entre tais elementos definirá a intensidade das alterações espaciais que ocorrerão no meio onde se localiza a rede.

\subsubsection{Teoria dos grafos no estudo de redes de transporte}

Os termos da teoria dos grafos usados no transporte podem ser relacionados com objetos geográficos reais onde os nós e arcos representam características específicas desses objetos. A teoria dos grafos destaca-se pelo auxílio a solução de problemas existentes no campo do transporte, a saber: capacidade de via, rota de caminho mínimo, estudo de mobilidade, entre outros (ALMEIDA et al., 2003).

A representação de um dado sistema de transportes sob o enfoque da teoria dos grafos é associada ao conceito usual atribuído as redes. Nesse caso, uma rede de transporte é constituída por nós e arcos onde os nós são considerados importantes pontos no espaço e os arcos são ligações físicas entre tais pontos.

\subsubsection{Custos em redes de transporte}

Grande parte das análises em transporte refere-se ao custo generalizado. Esse é o custo de uma viagem tal como percebido pelo usuário da rede, e é uma medida composta de todos os fatores que são relevantes a tomada de decisão. Os mais significantes componentes são os custos diretos, como taxas, combustível, etc., e as despesas que são função da qualidade do serviço. Ao se trabalhar, apenas com os custos diretos de transporte, serão determinados níveis de referência em termos de preços de fretes para a determinação de rotas, cada rota constituída por arcos. Assim, é possível avaliar diferentes rotas e identificar qual oferece menor custo (BELL e IIDA, 1997).

\subsubsection{Custos de transporte em um arco}

Na representação de rede de transportes, uma forma de associar custo aos arcos pode ser em termos de deslocamento ou restrição de capacidade e operação, especialmente a restrição associada a técnicas disponíveis e condições do sistema viário, as quais são representadas pelos arcos. A notação do custo de arco é, em geral, uma função do fluxo do arco (POTTS e OLIVER, 1972). O fluxo considerado nesse estudo refere-se ao transporte de carga, onde o custo operacional de transporte de carga é usado como custo a ser analisado no deslocamento de veículos pelos arcos. Considerando o modelo usado pela maioria dos operadores de transporte de carga no Brasil, o custo de transporte no arco é definido matematicamente pela Equação (1). 


$$
c l_{i}=c f l_{i}+c v l_{i} \quad \text { Eq. [1] }
$$

Onde:

$C l_{i}=$ custo de transporte no arco $I_{i}$;

$\mathrm{Cfl}_{i}=$ custo fixo por dia no arco $I_{i}$;

$C V I_{i}=$ custo variável por quilômetro no arco $I_{i}$.

Como verificado na Equação (2), adotouse o esquema de separação usual em custos fixos e custos variáveis, os quais são utilizados com frequência pelos transportadores de carga (Filho e Gameiro, 2001). O custo fixo e variável no arco $\left(l_{i}\right)$ pode ser representado pelas Equações (2) e (3) respectivamente.

$$
\begin{gathered}
c f l_{i}=\frac{c f v}{V m \times h t d} \times D_{i} \\
c v_{i}=c W \times D_{i}
\end{gathered}
$$

Onde:

$\mathrm{Cfl}_{i}=$ custo fixo de transporte no arco $I_{i}(\mathrm{R} \$)$;

$c f V=$ custo fixo diário do veículo $(\mathrm{R} \$)$;

$D_{i}=$ comprimento do arco $I_{i}(\mathrm{~km})$;

$V m=$ velocidade média do veículo no arco $l_{i}(\mathrm{~km} / \mathrm{h})$;

$h t d=$ horas trabalhas por dia (h);

$C V I_{i}=$ custo variável por quilômetro no arco $I_{i}(\mathrm{R} \$$ );

$C W=$ custo variável do veículo (R\$).
Substituindo as Equações (2) e (3) na Equação (1), tem-se a Equação (4) como segue:

$$
c l_{i}=\frac{c f v}{V m \times h t d} \times D_{i}+c w \times D_{i}
$$

Dividindo o custo de transporte em um determinado arco pela capacidade de carga do veículo $(P)$ a ser usado no transporte, tem-se a Equação ( $5 a$ e $5 b$ ) expressa em termos de custo operacional por tonelada deslocada nos arcos.

$$
c l_{i}=\frac{\frac{c f v}{V m \times h t d} \times D_{i} \div+\left(c v \vee \times D_{i}\right)}{P}
$$

$\mathrm{Ou}$

$$
c_{i}=\frac{\frac{c f v}{V m \times h t d}+c V v \div}{P} \times D_{i}
$$

\section{METODOLOGIA PARA A ELABORAÇÃO DE REDE DE TRANSPORTE MULTIMODAL DE CARGA}

A metodologia para elaboração de rede de transporte multimodal de cargas é constituída por oito etapas conforme apresentado pelo fluxograma da Figura 1.

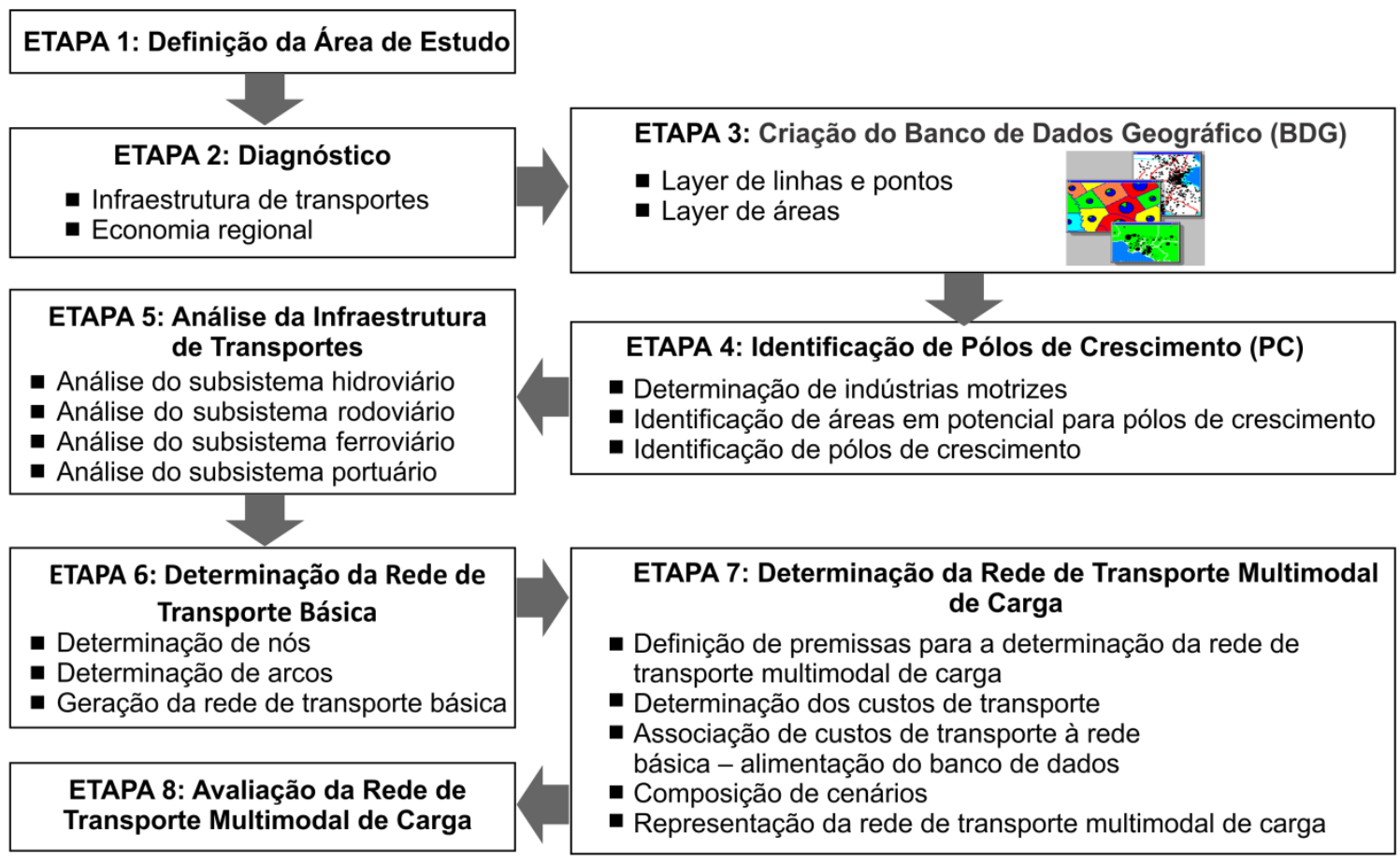

FIGURA 1: Metodologia para a elaboração da rede de transporte multimodal de cargas. 
4. ELABORAÇÃO DA REDE DE TRANSPORTE MULTIMODAL DE CARGA PARA A REGIÃO AMAZÔNICA

Nesse item são apresentadas as atividades desenvolvidas para a elaboração da rede de transporte multimodal de carga para a Região Amazônica como forma de validar a metodologia apresentada na Figura 1. $\mathrm{Na}$ elaboração da rede foram identificados os principais pólos de crescimento econômico, elementos essenciais na estruturação da rede de transporte. Em seguida, foram coletadas e analisadas as informações quanto à infraestrutura de transportes, necessárias à configuração das vias de ligação que estruturam a rede.

\section{ETAPA 1: DEFINIÇÃO DA ÁREA DE ESTUDO}

A área de estudo desse trabalho é a Região Amazônica Brasileira, a qual cobre uma área de $5.217 .423 \mathrm{~km}^{2}$. Tal área compreende a totalidade da região norte, a maior parte da região centro-oeste e parte da região nordeste no que se refere ao estado do Maranhão (ADA, 2013). A Figura 2 apresenta a delimitação geográfica da Região Amazônica considerada no estudo, a qual é constituída por 792 municípios que formam nove estados.

\section{ETAPA 2: DIAGNÓSTICO}

A fim de desenvolver uma rede de transporte multimodal de carga, torna-se necessário realizar um diagnóstico a respeito da infraestrutura de transportes e da economia regional, a qual é apresentada como segue.

\section{Sub-etapa 2.1: diagnóstico regional da infraestrutura de transportes}

As facilidades de transporte na Região Amazônica estão sendo consolidadas gradualmente e seu desenvolvimento depende do dinamismo da economia regional. É necessário conhecer a situação atual da infraestrutura de transportes da região, para, em um segundo momento fazer uma análise das condições de uso e identificar a necessidade de sua expansão.

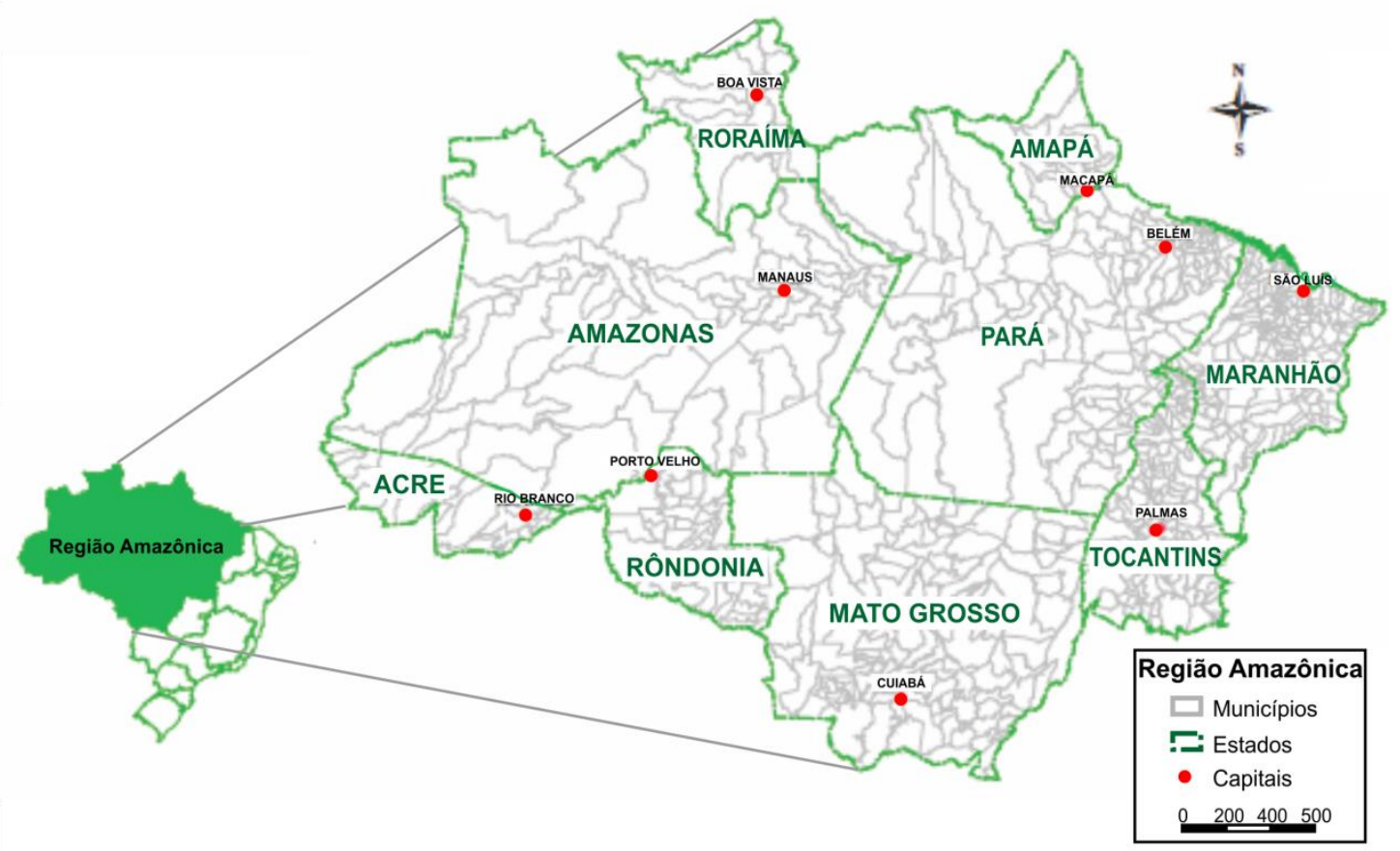

FIGURA 2: Delimitação geográfica da Região Amazônica Brasileira. FONTE: (INPA, 2003). 
- Subsistema de transporte hidroviário interior: a Região Amazônica é constituída basicamente pela bacia do rio Amazonas, a qual representa um quinto $(1 / 5)$ de toda água doce do mundo (INPA, 2003). Os rios são apoiados pelos períodos de chuva, e são considerados praticamente os únicos meios de transportes da grande maioria das comunidades locais. Existem mais de $20.000 \mathrm{~km}$ de rios ligando comunidades distantes. Outra bacia hidrográfica localizada na mesma região é de igual forma importante, a bacia do Rio Tocantins.

- Subsistema portuário: a vasta rede hidroviária da Amazônia são servidas por um subsistema portuário que no momento atende razoavelmente aos fluxos existentes. Segundo as características técnicas que determinam a movimentação de cargas e passageiros, podese distinguir as instalações portuárias em dois grupos, os portos marítimos e os terminais hidroviário (Almeida et. al., 2004).

- Subsistema rodoviário: o subsistema rodoviário da Região Amazônica foi concebido com o papel de complementar o subsistema hidroviário, e tem como objetivo assegurar a construção de vias alimentadoras. Vale ressaltar as poucas rodovias existentes, devido principalmente as condições geológicas do solo da região, as quais não são consideradas apropriadas à construção de rodovias (Almeida et. al. 2004).

- Subsistema ferroviário: o objetivo das ferrovias da Região Amazônica é atender o escoamento de grandes volumes de minérios, transportando-os das minas aos portos. 0 subsistema ferroviário da Região conta com quatro estradas de ferro em operação, a saber: Estrada de Ferro Amapá (EFA); Estrada de Ferro Jarí (EFJ); Estrada de Ferro Trombetas (EFT); Estrada de Ferro Carajás (EFC); Ferrovia NorteSul (FNS) (ANTT, 2007).

\section{Sub-etapa 2.2: diagnóstico econômico regional}

A economia da Região Amazônica é sustentada pelo desenvolvimento de atividades econômicas predominantes, especificamente atividades minerais, florestais e agrícolas. Tais atividades se desenvolvem principalmente pela exploração e/ou beneficiamento de alguns produtos da região. Os vinte principais produtos que sustentam a economia da Região Amazônica podem ser classificados dentro dos respectivos grupos de atividades:

- Minerais: são caracterizadas pela extração de minerais, entre os quais se destacam: minério de ferro, petróleo, minério de alumínio, caulim, estanho. $O$ minério de ferro e o petróleo são os principais produtos;

- Florestais: o desenvolvimento de atividades florestais na Região Amazônica é caracterizado pela extração e/ou beneficiamento principalmente de madeira e látex;

- Agrícolas: são caracterizadas principalmente pela produção de alguns produtos, a saber: soja, arroz, mandioca, algodão, milho, café. Dentre estes, maior destaque é dado a soja, ao arroz e a mandioca.

\section{ETAPA 3: CRIAÇÃO DO BANCO DE DADOS GEOGRÁFICOS (BDG)}

Um banco de dados geográficos foi concebido usando o Sistema de Informação Geográfica (SIG). Tal banco é formado por dados coletados no diagnóstico. O SIG permitiu a manipulação de três tipos de camadas (layers), a saber:

- Layer de pontos representando o subsistema portuário, constituído pelos portos marítimos e terminais hidroviários, e suas principais características físicas tais como: docas, píer de atracação e acostagem; área instalada e capacidade de armazéns; largura e profundidade de cais, bacias de evolução, e canal de acesso. Além disso, a quantidade movimentada das principais cargas referente ao ano de 2000;

- Layer de linhas representando os rios da bacia Amazônica e do Tocantins, e as suas principais características, como: período de águas baixas e altas, comprimento, largura e profundidade. 
Outros layers tipo linhas também são criados referentes às rodovias e ferrovias;

- Layer de áreas representando os 792 municípios que constituem a Região Amazônica foi criado. Um layer é criado para cada produto identificado na etapa de diagnóstico em um total de vinte. Aos vintes layers são associadas informações quanto a valor de produção dos municípios onde tais atividades econômicas são desenvolvidas, e quantidade produzida.

\section{ETAPA 4: IDENTIFICAÇÃO DOS PÓLOS DE CRESCIMENTO (PC)}

A identificação dos Pólos de Crescimento na Região Amazônica foi feita por meio de três sub-etapas: determinação de indústrias motrizes; identificação de áreas em potencial para PC; identificação de PC. Tais sub-etapas foram elaboradas utilizando as bases teóricas que constituem a Teoria de Perroux e as ferramentas estatísticas da Análise Espacial.

\section{Sub-etapa 4.1: determinação de indústrias motrizes}

Nesta etapa foram determinadas às indústrias motrizes. Segundo a teoria de Perroux, parte-se da identificação de produtos produzidos na Amazônia para identificar atividades econômicas atividades econômicas existentes, e em consequência determinar as indústrias motrizes, que serão fundamentais para a identificação dos PC. Para a identificação dos produtos e das atividades econômicas, foi preciso coletar os valores de produção dos vinte produtos desenvolvidos na região, analisá-los, e determinar, por meio da Curva $A B C$, quais são considerados economicamente mais importantes. A Tabela 1 apresenta a lista dos vinte produtos analisados, segundo os valores de produção em (R\$).

As linhas da Tabela 1 em destaque em tom de cinza apresentam os produtos mais importantes (classes A e B) em termos de valor de produção, isso segundo demonstra a Curva $A B C$ (Figura 3). Conforme a orientação para a classificação das classes tem-se:

- Classe A: 4, 20\% dos produtos representam $54,33 \%$ do valor total da produção na Região, exigindo assim atenção maior com tais produtos;

- Classe B: 6, 30\% dos produtos representa $13,23 \%$ do valor total da produção na Região, exigindo assim atenção mediana com tais produtos;

- Classe C: $10,50 \%$ dos produtos representa $32,44 \%$ do valor total da produção na Região, exigindo menos atenção para com este produto.

TABELA 1: Curva ABC - valor de produção dos produtos da Região Amazônica.

\begin{tabular}{|c|c|c|c|c|}
\hline Produtos & Valor de Produção (R\$) & Valor de Produção Acumulado & $\%$ Sobre o Valor Total Acumulado & Classificação Ordenada \\
\hline Soja & $2.283 .324 .000,00$ & $2.898 .288 .980,00$ & 27,22883062 & 1 \\
\hline Ferro & $1.351 .064 .014,00$ & $4.249 .352 .994,00$ & 39,92 & 2 \\
\hline Arroz & $797.524 .000,00$ & $5.046 .876 .994,00$ & 47,41 & 3 \\
\hline Petróleo & $735.902 .790,00$ & $5.782 .779 .784,00$ & 54,3280302 & 4 \\
\hline Mandioca & $714.826 .000,00$ & $6.497 .605 .784,00$ & 61,04367388 & 5 \\
\hline Madeira & $693.594 .000,00$ & $7.191 .199 .784,00$ & 67,55984728 & 6 \\
\hline Algodão & $607.811 .000,00$ & $7.799 .010 .784,00$ & 73,27010698 & 7 \\
\hline Milho & $497.470 .000,00$ & $8.296 .480 .784,00$ & 77,94373561 & 8 \\
\hline Banana & $483.161 .000,00$ & $8.779 .641 .784,00$ & 82,48293413 & 9 \\
\hline Alumínio & $436.997 .218,00$ & $9.216 .639 .002,00$ & 86,58843337 & 10 \\
\hline Caulim & $306.290 .482,00$ & $9.522 .929 .484,00$ & 89,46596964 & 11 \\
\hline Café & $305.857 .000,00$ & $9.828 .786 .484,00$ & 92,33943343 & 12 \\
\hline Gás Natural & $289.828 .980,00$ & $10.118 .615 .464,00$ & 95,06231727 & 13 \\
\hline Pimenta-do-Reino & $140.897 .000,00$ & $10.259 .512 .464,00$ & 96,38601569 & 14 \\
\hline Feijão & $106.804 .000,00$ & $10.366 .316 .464,00$ & 97,38941737 & 15 \\
\hline Estanho & $101.772 .424,00$ & $10.468 .088 .888,00$ & 98,34554842 & 16 \\
\hline Bauxita & $67.782 .073,00$ & $10.535 .870 .961,00$ & 98,98234709 & 17 \\
\hline Calcário & $52.005 .590,00$ & $10.587 .876 .551,00$ & 99,47092895 & 18 \\
\hline Latex & $35.149 .000,00$ & $10.623 .025 .551,00$ & 99,8011466 & 19 \\
\hline Cromo & $21.166 .338,00$ & $10.644 .191 .889,00$ & 100 & 20 \\
\hline
\end{tabular}


Os produtos mais importantes economicamente para a Região Amazônica são nesta ordem: soja, ferro, arroz, petróleo, mandioca e madeira. As atividades de extração e produção de tais produtos foram usadas para determinar as indústrias motrizes que nortearam a identificação dos PC. Nesse artigo, a título de simplificação, são apresentadas as atividades realizadas para a identificação dos pólos relacionados ao produto madeira, sendo que o mesmo foi feito com relação a todos os outros cinco produtos da região Amazônica.

Os produtos mais importantes economicamente para a Região Amazônica são nesta ordem: soja, ferro, arroz, petróleo, mandioca e madeira. As atividades de extração e produção de tais produtos foram usadas para determinar as indústrias motrizes que nortearam a identificação dos PC. Nesse artigo, a título de simplificação, são apresentadas as atividades realizadas para a identificação dos pólos relacionados ao produto madeira, sendo que o mesmo foi feito com relação a todos os outros cinco produtos da região Amazônica.

\section{Sub-etapa 4.2: identificação de áreas em potencial para pólos de crescimento}

As áreas em potencial são consideradas porções do espaço dentro da Região Amazônica representados pelos municípios que, em primeira análise, possuem os maiores valores de produção dos produtos das indústrias motrizes. Para identificar tais áreas foi necessário executar duas atividades: geração de mapas temáticos da distribuição da variável escolhida; e análise da distribuição espacial da variável para a identificação de áreas em potencial. Gerou-se o mapa da distribuição espacial dos valores de produção da madeira, como exemplo (Figura 4). Realizaram-se análises da distribuição espaciais em tal mapa com o propósito de identificar áreas constituídas por grupos de municípios que possuem os maiores valores de produções.

Na Figura 4, observam-se cinco regiões delimitadas (R1ma, R2ma, R3ma, R4ma, R5ma), que possuem os maiores valores de produção. Percebe-se que, apesar da produção de madeira estar distribuída em quase toda a Região Amazônica, os municípios com maiores valores de produção estão localizados no estado do Pará (regiões sul, sudeste, extremo norte e centrooeste). Essas regiões, em uma primeira análise, podem ser consideradas potencialmente como pólos. Todavia, se faz necessário confirmar/validar por meio da estatística espacial, se tais áreas são pólos de crescimento.

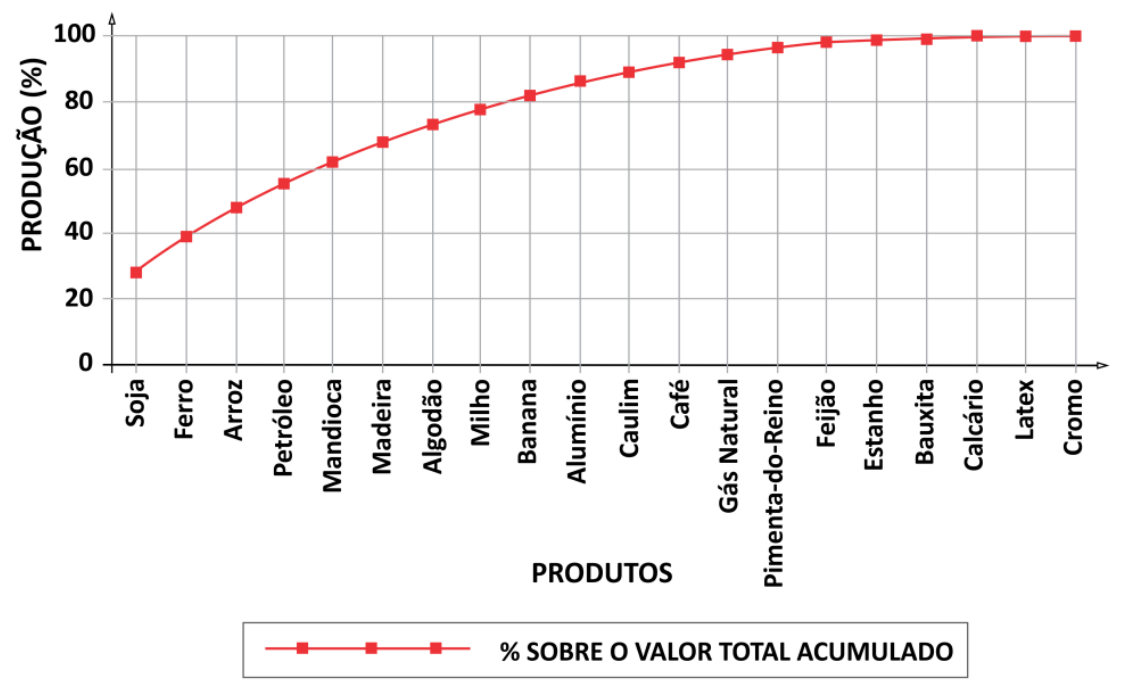

FIGURA 3: Curva $A B C$ do valor de produção dos produtos da Amazônica. FONTE: IBGE (2001a); IBGE (2001b) e DNPM (2001). 


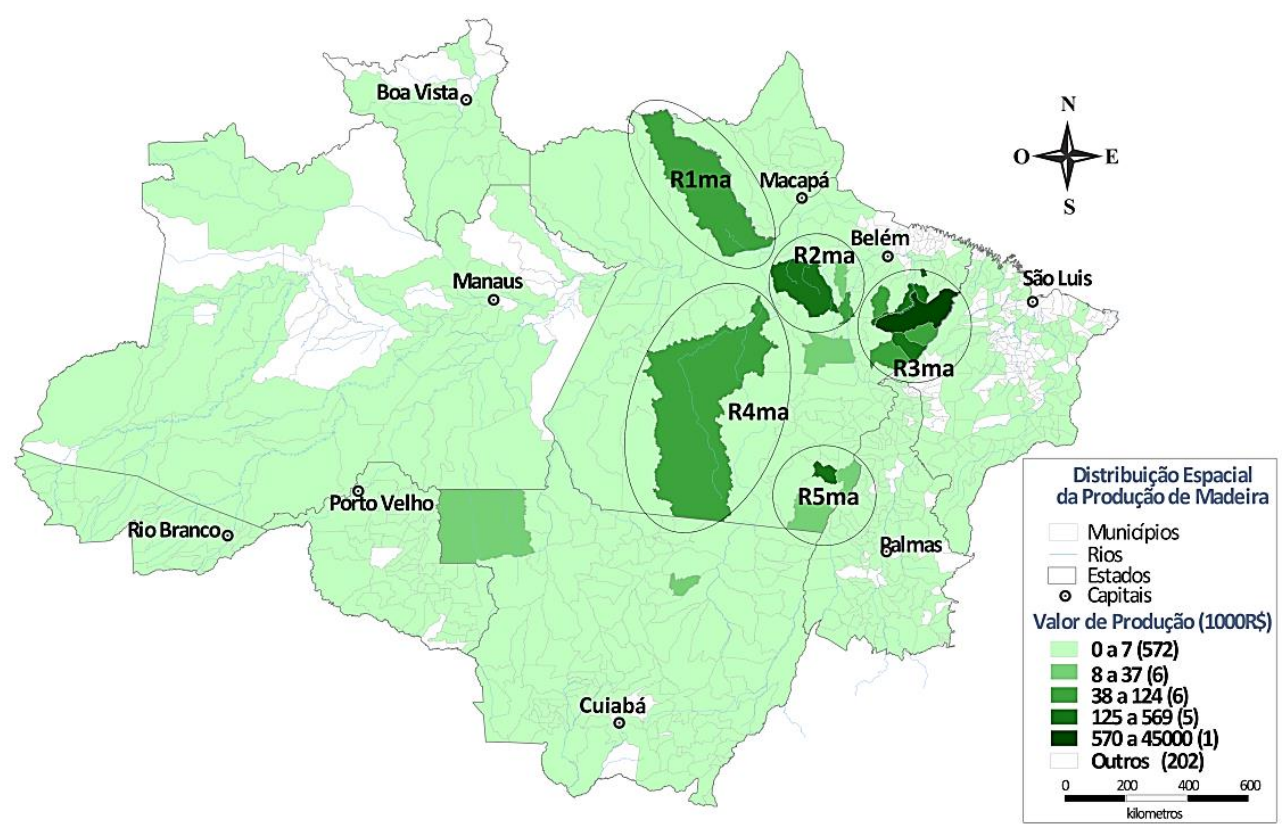

FIGURA 4: Distribuição espacial do valor de produção da madeira na Amazônia. FONTE: IBGE (2001b).

\section{Sub-etapa 4.3: identificação de pólos de crescimento}

Essa sub-etapa vale-se da estatística espacial, seus índices e mapas que auxiliam na tomada de decisão. O primeiro índice que se determinou foi o Índice Global de Moran que expressa o grau de homogeneidade ou heterogeneidade da área estudada. Esse valor foi determinado em um software livre. $O$ índice calculado foi de $33 \%$, indicando que a região em estudo possui dependência espacial, porém baixo grau de homogeneidade, ou seja, poucas são as áreas que possuem mesmo padrão de agregação. Em seguida, gerou-se o Box Map a fim de determinar como as áreas da região em estudo estão se relacionado entre si, como mostra a Figura 5. Por meio deste é possível notar que existe um aglomerado de áreas bem definido com mesmo padrão de agregação. As áreas agregadas de cor vermelha e que se relacionam mais fortemente (high-high), devido aos valores altos dos atributos, coincidem com as áreas anteriormente identificadas como possíveis pólos de crescimento.

A identificação das áreas que são significativas a $95 \%$ de confiança é dada por meio do Moran Map (Figura 6). As áreas em cor vermelha do Moran Map possuem forte correlação e são significativos, enquanto que os demais não possuem tal padrão, por estarem em uma região instável. Note-se que algumas das áreas significantes, identificadas no mapa Figura 6 , coincidem com as áreas das regiões inicialmente delimitadas como possíveis PC (Figura 4). Concluise que, a simples visualização da distribuição espacial da variável não é suficiente para a identificação dos PC, ou seja, é necessário se valer da estatística espacial.

O município de Aripuanã, na Figura 6, identificado como significativo é um exemplo que merece destaque, pois este município, a princípio, não foi identificado como área em potencial, mas quando se gerou o Box Map, observou-se que este município possui padrão elevado de autocorrelação positiva (high-high). O Moran Map da Figura 6 confirmou estatisticamente que 0 município de Aripuanã é um PC. A Figura 6 apresenta clusters constituídos por municípios de valores de produção de madeira significativos. Tais clusters são os PC na Região Amazônica quanto ao valor de produção de madeira, os quais são representados pelos seguintes municípios: Paragominas; Redenção; Portel; Almeirim; Altamira; e Aripuanã. Em seguida, identificou-se os centros dos PC de cada produto. Isto foi feito, obedecendo os seguintes critérios: 
- Utilizaram-se os Moran Map gerados para os produtos selecionados, pois estes mapas apresentam os grupos de municípios significativos estatisticamente. No mapa de cada produto, identificaram-se os grupos de municípios (clusters) que constituíram os PC;
- Para cada cluster, determinou-se um município que representasse o seu PC;

- A seleção do município que representa cada PC foi feita em função do maior valor de produção e da acessibilidade quanto a infraestrutura de transporte existente.

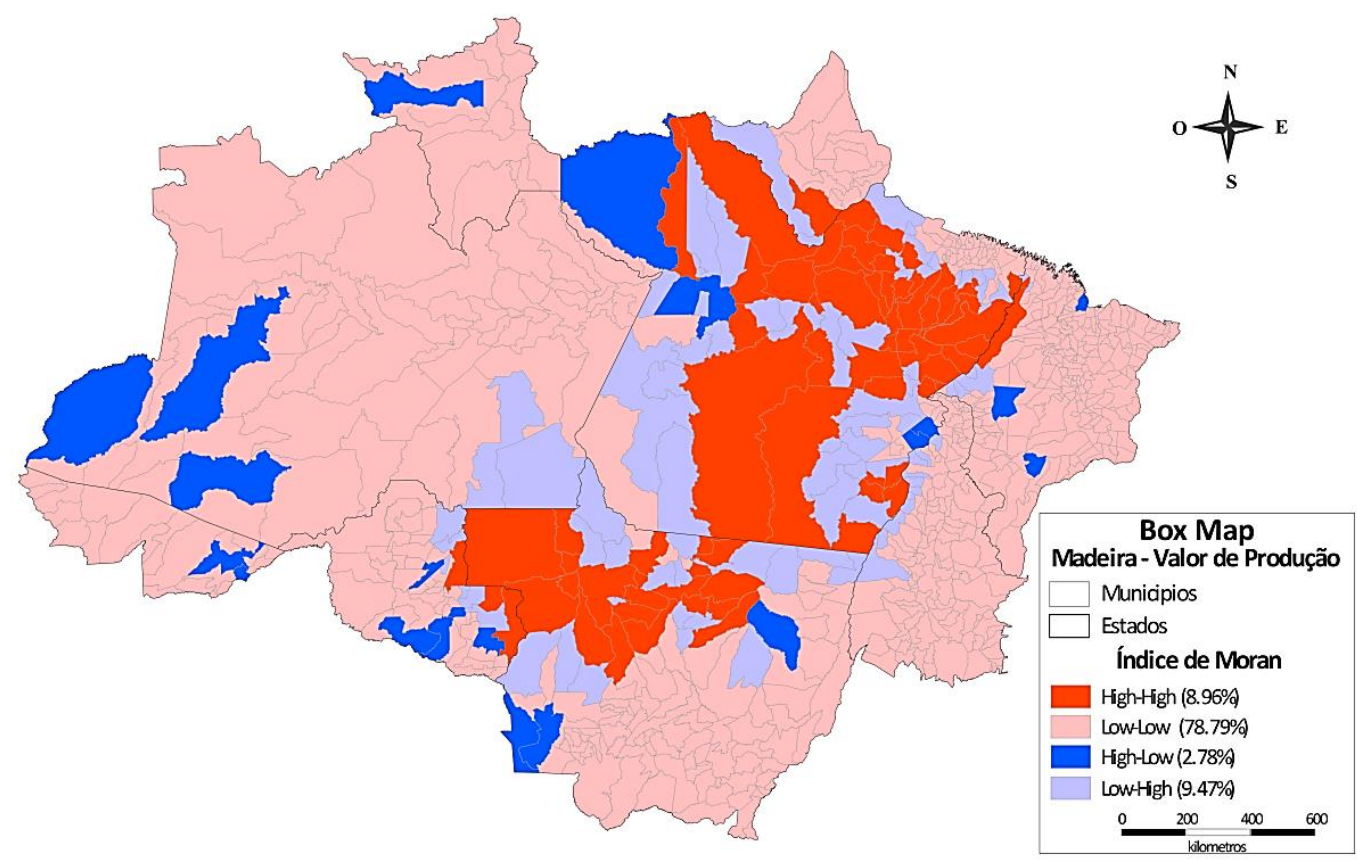

FIGURA 5: Box Map do valor de produção da madeira na Região Amazônica.

FONTE: Próprio autor.

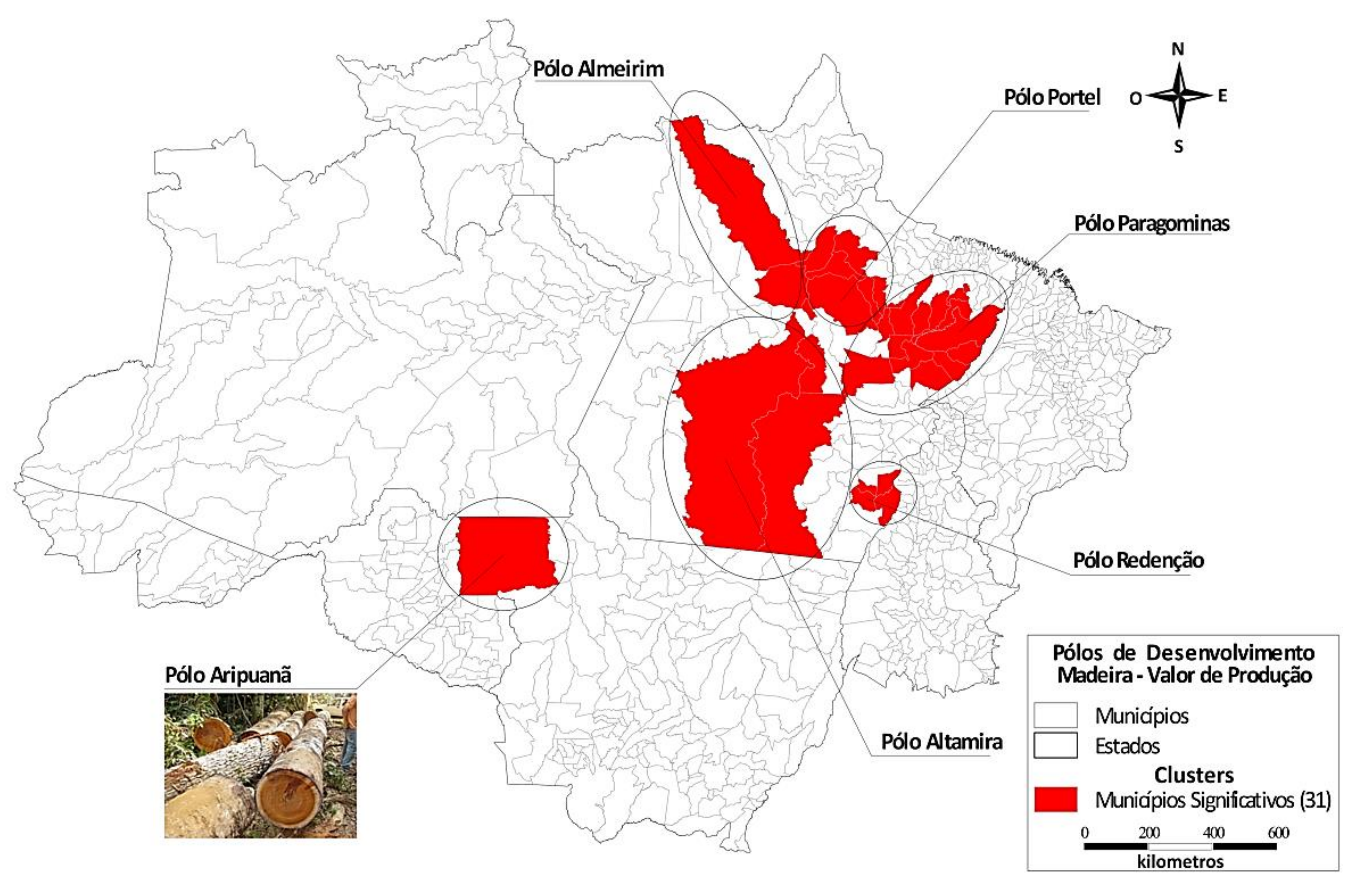

FIGURA 6: Moran Map do valor de produção de madeira na Região Amazônica.

FONTE: Próprio autor. 
ETAPA 5: ANÁLISE DA INFRAESTRUTURA DE TRANSPORTES

A infraestrutura de transportes, segundo a Teoria dos Pólos de Crescimento e Pólos de Desenvolvimento, pode ser compreendida como os meios físicos por onde os efeitos de crescimento e desenvolvimento oriundo dos pólos são irradiados, nesse caso, são chamados de eixos de desenvolvimento. A infraestrutura de transportes, sob a ótica da Teoria dos Grafos, pode ser traduzida por um conjunto de arcos e nós que constituirão uma rede de transportes, a qual facilitará o escoamento dos produtos produzidos na região.

As análises realizadas na infraestrutura de transportes da Região Amazônica foram necessárias para identificar às linhas de desejo a serem usadas na definição dos arcos que constituem a rede de transporte básica. Além disso, foi possível identificar os principais "gargalos" e/ou locais de impedância que afetariam os fluxos de veículos e conseqüentemente $\mathrm{o}$ transporte de cargas. Como cada modo de transporte tem sua peculiaridade, análises distintas foram realizadas para cada subsistema de transportes. Alguns fatores foram considerados na execução das análises, a saber: análise de navegabilidade de rios; análise de utilização das rodoviárias para o deslocamento de veículos de carga; análise de movimentação de cargas nos portos e ferrovias.

\section{ETAPA 6: DETERMINAÇÃO DA REDE DE TRANSPORTE BÁSICA}

Essa etapa foi realizada baseada em três atividades: determinação de nós; determinação de arcos; e geração da rede de transporte básica.

\section{Sub-etapa 6.1: determinação de nós}

A primeira atividade executada foi à determinação dos nós, neste caso, foi necessário distinguir dois tipos de nós, centróides e de conexão:
- Nós centróides: dentro de cada cluster, que constitui os PC, é identificado o município que possui o maior valor de produção, o qual é definido como o nó centróide de seu respectivo cluster. Foram determinados para todos os PC os seus respectivos nós centróides, num total de vinte e seis, a saber: Almeirim, Altamira, Aripuanã, Aurora do Pará, Campos de Júlio, Coari, Diamantino, Guarantã do Norte, Itacoatiara, Laranjal do Jarí, Manicoré, Nova Ubiratã, Novo São Joaquim, Paragominas Paranatinga, Parauapebas Parintins, Portel, Pium, Redenção, São Félix do Xingú, São Mateus do Maranhão, Sena Madureira, Sinop, Tarauacá, e Tefé;

- Nós de conexão: foram definidos como nós de conexão os pontos de interseção entre dois diferentes arcos do mesmo subsistema de transporte, ou pontos de interseção entre diferentes subsistemas de transportes, funcionando como terminal intermodal.

\section{Sub-etapa 6.2: determinação de arcos}

A determinação dos arcos foi feita usando as vias de transportes identificadas na etapa cinco. $\mathrm{Na}$ análise da infraestrutura de transporte, cada subsistema de transporte foi analisado em um mapa temático distinto, feito isso, os mapas temáticos foram exportados para outra plataforma SIG onde foi criada uma nova e única estrutura geográfica constituída por arcos (rios navegáveis, rodovias implantadas e ferrovias) e nós de conexão.

\section{Sub-etapa 6.3: geração da rede de transporte básica}

Como última atividade constituinte da etapa (6), tem-se a geração da rede de transporte básica, a qual o obteve-se como produto um mapa temático constituído por arcos e nós. A geração da rede foi feita por meio da técnica de sobreposição de mapas temáticos (Overlap Thematic Maps), utilizando dois mapas temáticos distintos, um constituído por nós centróides e outro por arcos e nós de conexão. A Figura 7 apresenta a configuração geográfica da rede de transporte básica gerada para a Região Amazônica. 


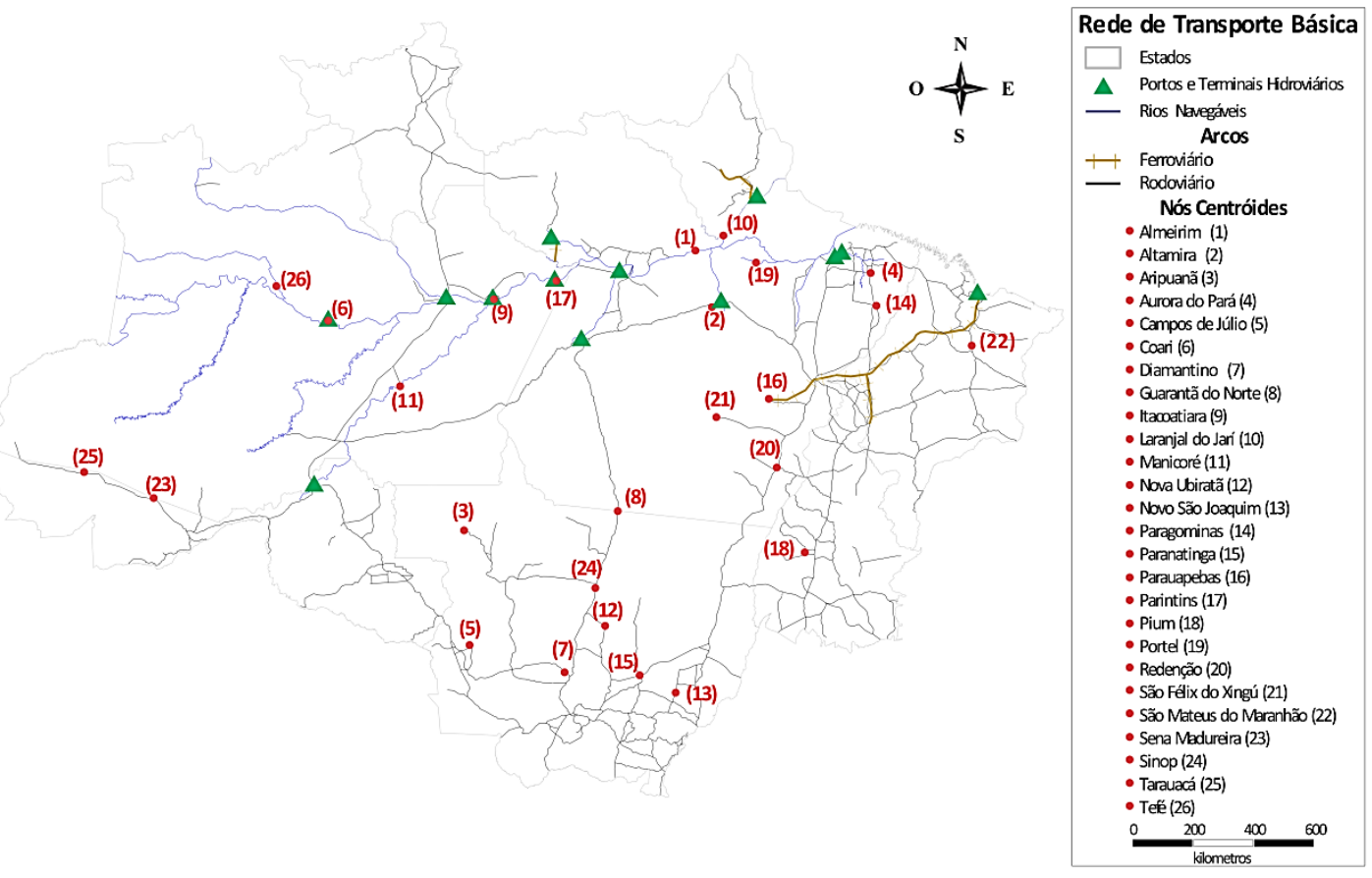

FIGURA 7: Configuração da rede de transporte básica na Região Amazônica. FONTE: Próprio autor.

\section{ETAPA 7: DETERMINAÇÃO DAS REDES DE TRANSPORTE MULTIMODAL DE CARGA}

Esta etapa é fundamentada na Teoria dos Grafos. Algumas atividades foram realizadas para a determinação das três redes de transporte multimodal de carga, a saber: definição de pressupostos para o desenvolvimento da rede de transporte multimodal de carga; determinação dos custos de transporte; associação de custos de transporte à rede básica - alimentação do banco de dados; composição de cenários; e a representação das redes de transporte.

Sub-etapa 7.1: definição de pressupostos para o desenvolvimento da rede de transporte multimodal de carga

Os pressupostos definidos para o desenvolvimento das redes foram:

- Foram criados três cenários que representem situações distintas (statu quo, investimentos em infraestrutura de transportes, e estratégica) e que são fundamentais para a concepção das três redes;

- A rede considerada é representada por um grafo direto;

- As viagens tem origem nos nós centróides;
- Foi definida uma rota de custo mínimo para cada PC. Todos os arcos da rede de transporte básica foram considerados na determinação dos caminhos mínimos;

- No caso dos nós que representam os PC referentes à indústria motriz de produção de mandioca, consideraram-se as capitais estaduais como destinos na análise de custo de transporte. Pois a maior parte da produção de mandioca é consumida na própria região, e como a população da região se concentra nas capitais, supõe-se que as capitais podem representar os destinos de viagens geradas por tais nós centróides;

- Os portos marítimos da região de estudo, por desempenhar a função de porto de exportação de produtos, foram considerados os nós destinos das viagens geradas pelos nós centróides que representam os PC;

- Nas análises de custos para a determinação dos caminhos mínimos são considerados os custos operacionais nos arcos e nos nós (transbordo);

- Foram definidos veículos de carga a serem considerados no cálculo do custo operacional de transporte. Além disso, algumas características dos veículos foram identificadas, 
a saber: itens que constituem os custos fixos (cfv) e variáveis (cvv) dos veículos; capacidade de carga $(\mathrm{P})$; velocidade média $(\mathrm{Vm})$; e o comprimento (Di) da via;

\section{Sub-etapa 7.2: determinação dos custos de transporte}

A determinação dos custos de transporte é importante para a identificação de caminhos mínimos, os quais permitiram a determinação das rotas que constituem as redes de transporte. Para isso, foram considerados dois tipos de custos, os custos operacionais de transporte nos arcos e os custos de transbordo (Equação 6).

$$
C^{\prime}{ }_{\text {rota }}=\sum_{i=1}^{I} c o a_{i}+\sum_{j=1}^{J} c n_{j}
$$

Onde:

$C^{\prime}{ }^{\prime}$ rota $=$ custo direto de transporte da rota de uma origem a um destino;

$\operatorname{coa}_{i}=$ custo operacional de transporte no arco $a_{i}$ por tonelada ( $\mathrm{R} \$ /$ ton);

$\mathrm{cn}_{j}=$ custo operacional de transporte no nó $n_{j}$ por

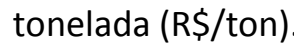

Para o calculo do custo operacional de transporte nos arcos, utilizou-se a Equação (5). Como a rede básica é constituída por arcos que representam rodovias, rios e ferrovias, para cada modo de transporte foi definido um veículo e para cada tipo de veículo foram coletados os valores correspondentes aos custos fixos e variáveis. Estes valores foram coletados em empresas transportadoras que operam na Região Amazônica.

Além dos custos operacionais de transporte nos arcos, outro custo foi determinado para a análise de caminho mínimo, o custo de transbordo. O custo de transbordo é admitido como o custo de transferência de cargas entre os diferentes modos de transportes. O custo de transbordo foi determinado usando a Equação (7). Apesar de existir uma série de tarifas cobradas nos portos, optou-se por usar as tarifas referentes a utilização da infraestrutura hidroviária $\left(T_{1}\right)$ e utilização da infraestrutura terrestre $\left(T_{2}\right)$, pois foram as únicas tarifas encontradas para os portos em análise.

$$
c n_{j}=T_{1 j}+T_{2 j}+O p_{j} \quad \text { Eq. [7] }
$$

Onde:

$c n_{j}=$ custo de transporte no nó $n_{j ;}$

$T_{i j}=$ tarifa portuária de utilização da infra-estrutura hidroviária ( $\mathrm{R} \$ /$ ton);

$T_{2 j}=$ tarifa portuária de utilização da infra-

estrutura terrestre (R\$/ton);

$O p_{j}=$ serviços de movimentação de carga (R\$/ton).

Quanto ao valor correspondente aos serviços de movimentação de carga $(O p)$, também conhecido como manuseio, adotou-se o valor de 3,00 R\$/ton para todos os portos e produtos considerados na análise, isso se justifica por dois motivos. Primeiro diz respeito à dificuldade em obtenção de dados de manuseio de cargas em cada porto e para cada produto, pois geralmente no Brasil, este serviço é executado por operadores privados, os quais não disponibilizam tais valores. Segundo, com a dificuldade em se obter tais dados, optou-se por usar a média dos valores de manuseio disponibilizado pelo Relatório Técnico da Antaq (2006), considerando todos os produtos movimentados nos portos e terminais hidroviários da Região Amazônica. No caso de transbordo em um terminal que não seja hidroviário ou porto, o custo de transbordo corresponde a parcela referente ao manuseio de carga $(O p)$.

\section{Sub-etapa 7.3: associação de custos de transporte a rede básica - alimentação do banco de dados}

Os custos operacionais de transporte foram determinados para os arcos e nós. No caso do custo operacional no arco $\left(c^{\circ} a_{i}\right)$, este foi determinado em função da extensão da via ou distância do $\operatorname{arco}\left(D_{i}\right)$. Assim, tanto as expressões determinadas para os modos de transporte quanto os valores calculados para cada porto foram usados para alimentar o banco de dados, associando-os por meio de um software de SIG.

\section{Sub-etapa 7.4: composição de cenários}

Nesse estudo, três cenários foram criados e consequentemente três redes de transporte multimodal de cargas foram elaboradas. O principal aspecto que diferenciou os três cenários diz respeito as modificações na 
infraestrutura de transportes da região e que resultou em modificações espaciais das estruturas das redes, a saber:

- Cenário 1 - statu quo: considerou-se a situação atual da infraestrutura de transportes existente. Este cenário possibilitou ter uma visão real da situação atual da Região Amazônica quanto aos deslocamentos dos principais produtos por meio da infraestrutura de transporte existente;

- Cenário 2 - investimentos em infraestrutura de transportes: foram admitidas alterações na infraestrutura de transportes da região considerando o Plano de Aceleração do Crescimento (PAC) elaborado pelo governo brasileiro que previu investimentos em infraestruturas voltados para todos os modos de transporte;

- Cenário 3 - estratégico: considera tanto os investimentos do PAC quanto a suposição de total navegabilidade dos rios Araguaia $\mathrm{e}$ Tocantins, permitindo a conexão da Região Amazônica com a região central do Brasil.

Considerando a rede básica elaborada na Etapa 6, foram determinadas rotas de custos operacionais de transporte mínimos entre os pares
O/D para os três cenários, obtendo-se um conjunto de rotas que ao final constituíram as estruturas de três redes de transporte. A determinação das rotas foi executada usando os valores dos custos operacionais calculados na sub-etapa 7.2 e um software de SIG que possui em sua base ferramental o algoritmo de Dijkstra para a determinação de caminhos mínimos.

\section{Sub-etapa 7.4: representação das redes de transporte multimodal de carga}

Nessa sub-etapa foram determinadas três redes de transporte (statu quo, PAC, e estratégico). Cada rede foi composta pelas rotas de custo mínimo, as quais foram identificadas para cada pólo de crescimento, representado por um nó centróide. Para cada origem (PC) foram considerados mais de um destino (porto) diferente, consequentemente obtiveram-se rotas distintas e custo operacionais diferentes para tais rotas. Ao final, foram identificadas as rotas que constituem cada rede, as quais são aquelas que possuem os menores custos operacionais de transporte. As redes determinadas para os cenários 1, 2 e 3 estão representadas pelas Figuras 8,9 e 10 respectivamente.

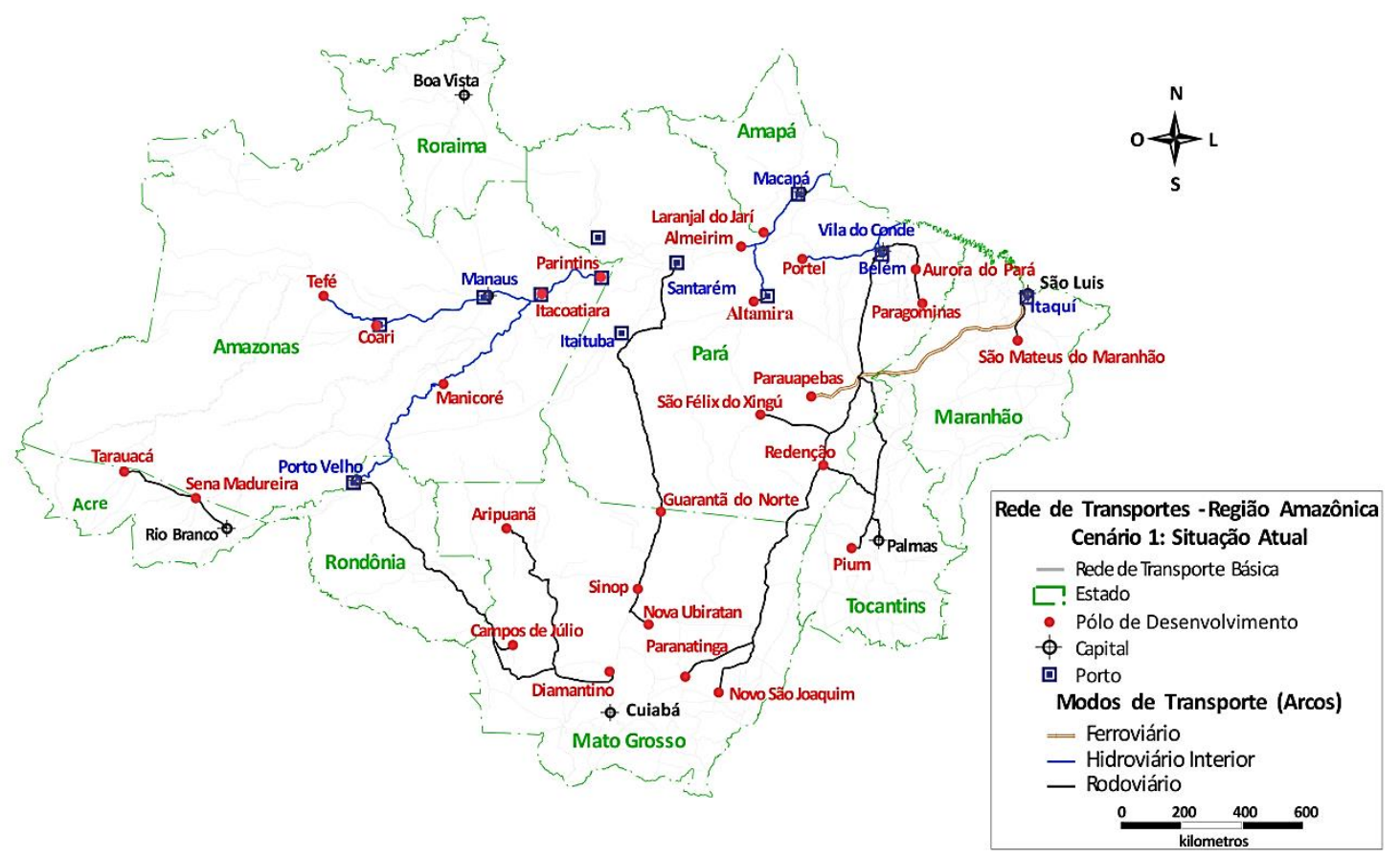

FIGURA 8: Rede de transporte multimodal de carga na Amazônia - Cenário 1. 


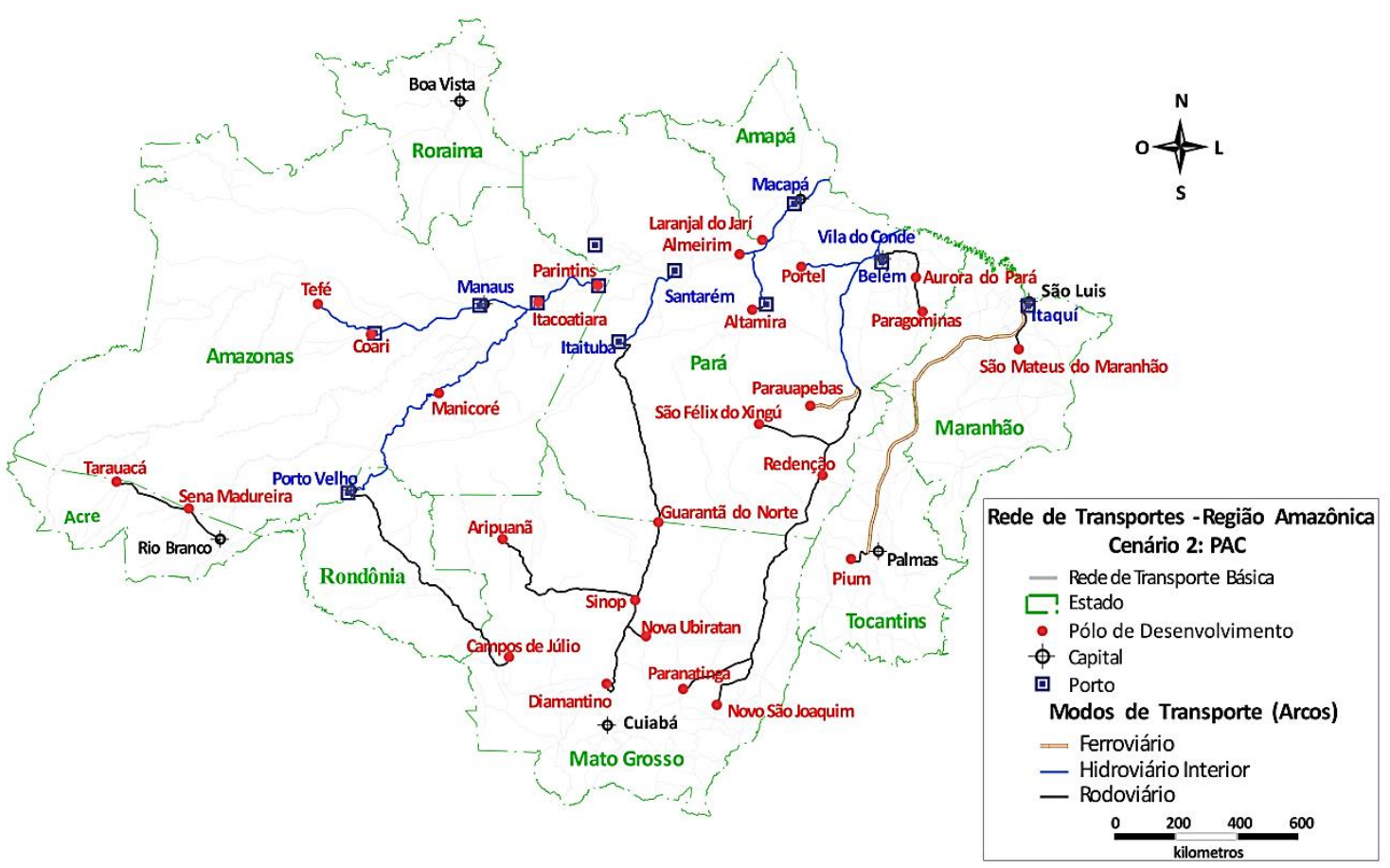

FIGURA 9: Rede de transporte multimodal de carga na Amazônia - Cenário 2.

FONTE: Próprio autor.

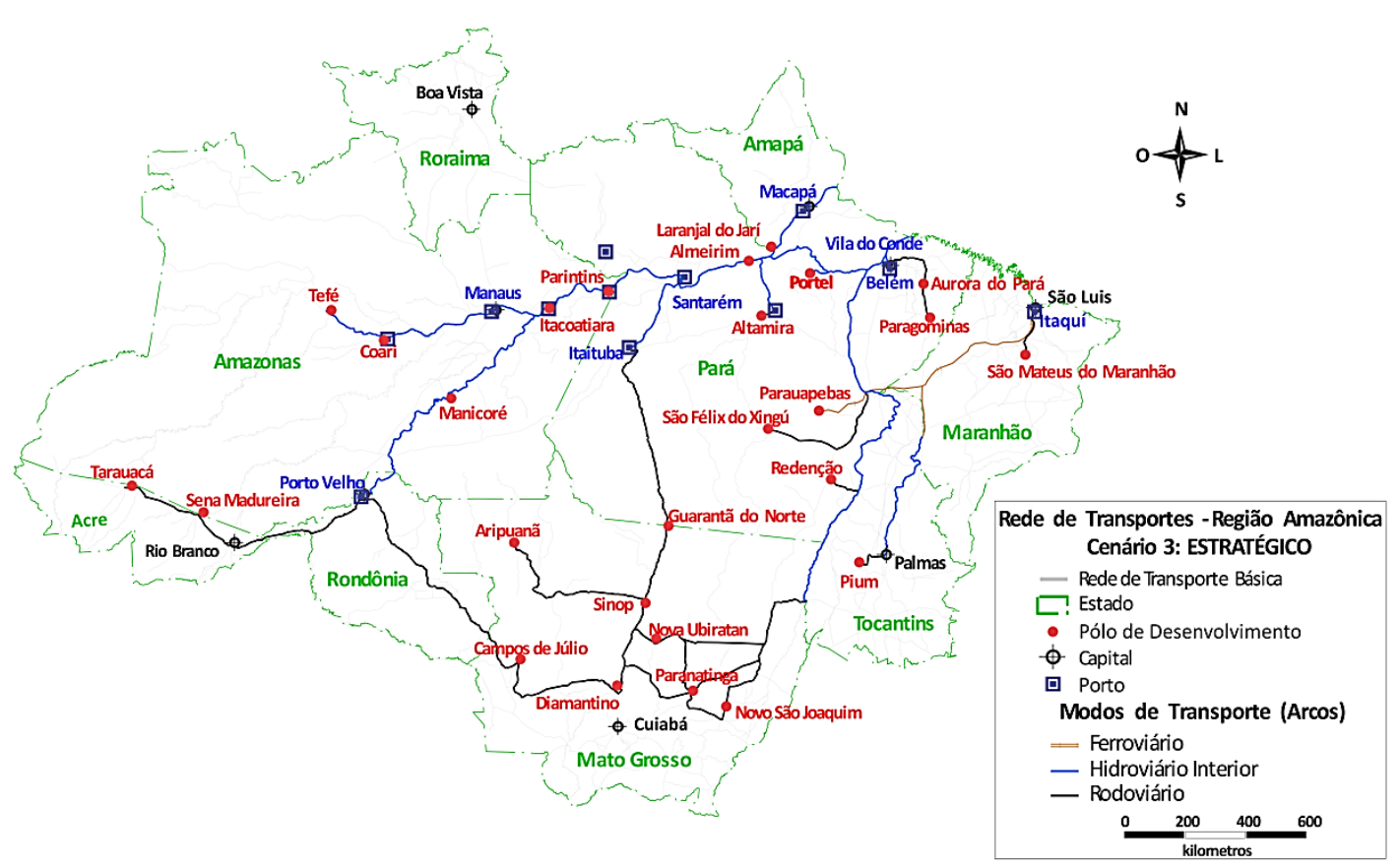

FIGURA 10: Rede de transporte multimodal de carga na Amazônia - Cenário 3.

FONTE: Próprio autor.

\section{ETAPA 8: AVALIAÇÃO DAS REDES DE TRANSPORTE MULTIMODAL DE CARGA}

A avaliação das redes considera o custo total, o que possibilitou identificar qual das redes possui o menor custo operacional de transporte. Assim, por meio de um software de SIG foi possível calcular o custo total, a saber:
- Cenário 1: o custo total da rede de transporte foi de $\mathrm{Ctr}=1.915,02 \mathrm{R} \$ /$ ton;

- Cenário 2: o custo total da rede de transporte foi de $\mathrm{Ctr}=1.548,38 \mathrm{R} \$$ /ton;

- Cenário 3: o custo total da rede de transporte foi de $\mathrm{Ctr}=1.662,10 \mathrm{R} \$$ /ton.

Comparando os custos totais das três 
redes, observa-se que a rede do cenário 1 possui o maior custo, seguido da rede do cenário 3 , e da rede do cenário 2 . Os valores obtidos indicam que os investimentos em infraestrutura reduzem os custos operacionais no transporte de carga. Merece destaque análise da rede do cenário 3, pois esta considera 0 transporte hidroviário interior como modo preponderante em sua estrutura. Apesar da tal rede possuir maior quantidade de arcos que representem rios, seu custo total é maior do que o custo total da rede 2 . Isso ocorreu por que na rede do cenário 3 foram acrescidos rotas para conectar as sub-redes que surgiram, as quais contribuíram para que o custo total de transporte se alterasse de $1.415,65 \mathrm{R} \$ /$ ton para $1.662,10 \mathrm{R} \$$ /ton.

\section{CONCLUSÕES}

Os estudos elaborados sobre transporte e desenvolvimento econômico no Brasil ainda são poucos, principalmente voltados à Região Amazônica. Observa-se que cada vez mais há necessidade de se realizar estudos e projetos alternativos que possibilitem melhor compreensão do papel do transporte no crescimento e desenvolvimento econômico regional.

No desenvolvimento desse estudo, quatro elementos foram priorizados, o transporte, o desenvolvimento econômico, a análise espacial, e a área de estudo. Tais elementos foram incorporados dentro da proposta metodológica elaborada no trabalho. Logo, avaliar de que forma estes elementos foram trabalhados na Região Amazônica é avaliar a importância da metodologia proposta. Assim, pode-se afirmar que a proposta é importante porque a metodologia é viável, o qual pode ser observado por meio dos resultados alcançados com a elaboração da rede de transporte para a Região Amazônica.

Construir uma rede de transporte na Região Amazônica que impulsione o desenvolvimento econômico, e consequentemente reduza as desigualdades socioeconômicas existentes entre a Amazônia e o restante do Brasil, é imprescindível por se tratar da primeira iniciativa real com tal enfoque. Desconsiderar o potencial econômico da região, e seus vastos recursos naturais como elementos fundamentais na elaboração de tal rede é um erro que foi repetidamente cometido durante anos na elaboração de políticas, planos e projetos de desenvolvimento econômico para a Amazônia que desconsideraram a relação entre transporte e desenvolvimento econômico.

Ao se estudar a relação entre transporte e desenvolvimento econômico foi possível desenvolver uma rede de transporte para a Região Amazônica baseada na Teoria dos Pólos de Crescimento e Pólos de Desenvolvimento e na Teoria dos Grafos. Como resultados, podem-se identificar:

- O estudo proposto considera técnicas não onerosas e teorias que visam ao desenvolvimento econômico regional na viabilização da infraestrutura de transportes;

- O uso da análise espacial no desenvolvimento da proposta permite manipular várias informações contribuindo para a tomada de decisão de forma satisfatória;

- O estudo proposto privilegia e aproveita em seu potencial os recursos naturais e de infraestrutura disponíveis na área de estudo;

- Com a aplicação da proposta metodológica é possível identificar os principais gargalos existentes na rede e testar propostas viáveis de desenvolvimento de mais pólos de crescimento.

No desenvolvimento do estudo foram identificadas algumas limitações, a saber:

- Dificuldade na obtenção de dados que reflitam as características socioeconômicas e de infraestrutura da região;

- Poucos estudos nacionais que considere a relação entre transporte e desenvolvimento econômico;

- Dados obtidos sobre a produção agrícola agregados por porções territoriais de grandes dimensões, dificultando o alcance de resultados mais precisos a respeito a distribuição espacial da variável utilizada. 
Sugestões de possíveis trabalhos relacionados ao tema abordado, a saber:

- Análise de sensibilidade de custo de transporte, capacidade e vulnerabilidade da rede de transportes;

- Análise da rede de transporte por meio de indicadores de acessibilidade e centralidade dos pólos de crescimento;

- Estudo de previsão do surgimento de novos pólos de crescimento que possam alterar a configuração atual da rede.

- Desenvolvimento de uma rede de transporte multimodal de carga que considere a demanda futura e alterações dinâmicas que podem ocorrer na estrutura espacial.

\section{REFERÊNCIAS BIBLIOGRÁFICAS}

ADA - Agencia de Desenvolvimento da Amazônia (2007). Amazônia Legal. Disponível: < http://www.ada.gov.br/index.php?option=com_conten t\&task=section\&id=9\&ltemid=47 >. Acessado em 2013.

ALMEIDA, C. F.; SANT'ANNA, J. A.; YAMAMOTO, K. Transport Network Development at Amazon Region: under Economic Growth Approach, Procceding of Infrastructure Planning, Japan Society of Civil Engineering (JSCE), vol. 28, Toyohashi, Japan, 2003.

ALMEIDA, C. F.; SANT'ANNA, J. A.; YAMAMOTO, K. Proposta de Rede de Transportes para a Região Amazônica, 20․ Congresso Nacional de Transporte Marítimo, Construção Naval e Offshore, Anais da Sociedade Brasileira de Engenharia Naval (SOBENA), Rio de Janeiro, Brasil, 2004.

ANDRADE, M. C. Espaço, Polarização \& Desenvolvimento: Uma Introdução a Economia Regional. Editora Atlas, 5a. ed., São Paulo, Brasil, 1987.

ANTAQ - Agência Nacional de Transporte Aquaviário. Acompanhamento Permanente dos Preços e do Desempenho Operacional dos Serviços Portuários: atualização dos indicadores de desempenho e preços dos serviços portuários nos principais portos brasileiros. Relatório Técnico, Brasília, Brasil, 2006

ANTT - Agência Nacional de Transportes Terrestres. Concessões Ferroviárias. Brasília, Brasil. Disponível em: <http://www.antt.gov.br/concessaofer/concessionarias fer.asp >. Acessado em 2007.
BANISTER, D.; BERECHMAN, Y. Transport Investiment and the Promotion of Economic Growth. Journal of Transport Geography, Pergamon, v.9, No.3, p. 209-218, 2001.

BELL, M. G. H.; IIDA, Y. Transportation Network Analisis. John Wiley \& Sons Ltda., England, 1997.

BOUDEVILLE, J. R. Lês espaces économiques. Paris, Presses Universitaries de France. Paris, France, 1961.

BRASIL. Ministério do Planejamento, Orçamento e Gestão. Secretaria de Planejamento e Investimentos Estratégicos -SPI. Estudo da Dimensão Territorial para o Planejamento: Volume III - Regiões de Referência / Ministério do Planejamento, Orçamento e Gestão. Secretaria de Planejamento e Investimentos Estratégicos. Brasília: MP, 2008.

CLEMENTE, A.; HIGACHI, H. Y. Economia e Desenvolvimento Regional. Editora Atlas S.A., São Paulo, Brasil, 2000.

COMBES, P.P.; LAFOURCADE, M.; MAYER, T. The TradeCreating Effects of Business and Social Networks: Evidence from France. Journal of International Economics, v. 66, n. 1, p. 1-29, 2005.

DINIZ, C. C. Dinâmica regional e ordenamento do território brasileiro: desafio e oportunidades. Belo Horizonte: UFMG/CEDEPLAR, 2013. (Texto para Discussão: n. 471).

DNPM - Departamento Nacional de Produção Mineral. Anuário Mineral Brasileiro - 2001. Brasília, Brasil, 2001.

DUPUY, G. El Urbanismo de las Redes: Teorias y métodos. Colégio de Ingenieros de Caminos, Canales y Puertos. Oikos-Tau, S.L. Industrias gráficas y editorial, Barcelona, España, 1998.

FERREIRA, A. Desenvolvimento regional: limites e possibilidades institucionais: um estudo de caso da região do Vale do Paraíba -RJ/Rio de Janeiro: UFRJ, 2012.

FILHO, J. V. C.; GAMEIRO, A. H. Sistemas de Gerenciamento de Transportes. 1a. Edição, Editora Atlas, São Paulo, Brasil, 2001.

GRIFFITH, D. A. Spatial Structure and Spatial Interaction: 25 Years Later. The Review of Regional Studies, v. 37, n. 1, p. 28-38, 2007.

HADDAD, P.R.; FERREIRA, C.M.C.; LODDER, C.A.; TOLOSA, H.C.; SCHICKLER, S. Planejamento Regional: métodos e aplicação ao caso brasileiro. Instituto de Planejamento Econômico e Social - IPEA/INPES, Monografia no. 8, 246p., Rio de Janeiro, Brasil, 1972. 
IBGE - Instituto Brasileiro de Geografia e Estatística. Produção Agrícola Municipal: Culturas Temporárias e Permanentes - 2000. Ministério doPlanejamento, Orçamento e Gestão, Rio de Janeiro, Brasil, 2001a.

IBGE - Instituto Brasileiro de Geografia e Estatística. Produção da Extração Vegetal e da Silvicultura - 2000. Ministério do Planejamento, Orçamento e Gestão, Rio de Janeiro, Brasil, 2001b.

INPA - Instituto Nacional de Pesquisas da Amazônia. Brasília, Brasil. Disponível em: < http://www.inpa.gov.br > Acessado em 2013, 2003.

KRAFT, G.; MEYER, J. R.; VALETTE, J. P. The Role of Transportation in Regional Economic Development. Lexington Books, Massachusetts, USA, 1971.

LIMA, A. C. C.; SIMÕES, R. F. Teorias do desenvolvimento regional e suas implicações de política econômica no pós-guerra: o caso do Brasil. Belo Horizonte: UFMG/Cedeplar, 2009.

LOPES, A. S. Desenvolvimento Regional Problemática, Teorias e Modelos. 5a. edição. Fundação Calouste Gulbenkian, Lisboa, Portugal, 2001.

PERROUX, F. L'économie du siécleme XX. 2a . ed. Paris, Press Universitaires de France, France, 1964.

POTTS, R. B.; OLIVER, R. M. Flows in Transportation Networks, Academic Press, Inc., New York, USA, 1972.

RICHARDSON, H. W. Elements of Regional Economics. Peguin Books Inc. Middlesex, England, 1969.

RODRIGUE, J.; COMTOIS, C.; SLACK, B. The Geography of Transport Systems. $1^{\mathrm{a}}$ ed. Routledge. London and New York, England, USA, 2006.

SANTOS, M. Economia Espacial: Criticas e Alternativas. 2a. ed., Editora da Universidade de São Paulo - EDUSP, São Paulo, 2003.

VASCONCELLOS, E. A. Transporte Urbano nos Países em Desenvolvimento: reflexões e propostas. 3a. ed. Editora Annablume, São Paulo, Brasil, 2000. 